\title{
ONTOGENESIS OF OLIVOCEREBELLAR RELATIONSHIPS
}

\section{Spontaneous Activity of Inferior Olivary Neurons and Climbing Fiber- mediated Activity of Cerebellar Purkinje Cells in Developing Rats ${ }^{1}$}

\author{
JEAN MARIANI ${ }^{2}$ AND JEAN-PIERRE CHANGEUX
}

Neurobiologie Moléculaire et Laboratoire Associé au Centre National de la Recherche Scientifique, Interactions Moléculaires et Cellulaires, Institut Pasteur, Paris, France

\begin{abstract}
During development of vertebrate cerebellum, a multiple innervation of each Purkinje cell (PC) by several climbing fibers (CFs) (Crépel, F., J. Mariani, and N. Delhaye-Bouchaud (1976) J. Neurobiol. 7: 567-578; Mariani, J., and J. -P. Changeux (1981) J. Neurosci. 1: 696-702) precedes the one-to-one relationship characteristic of the adult stage. In the present study, the spontaneous activity of inferior olivary neurons (whose axons constitute the CFs) and the spontaneous activity elicited in PCs by the CF system were investigated in developing rats.

Extracellular unitary recordings were obtained in medial and dorsal accessory olives from 249 neurons from 1-day-old to adult animals. The mean discharge rate varied from $0.19 \mathrm{spike} \cdot \mathrm{sec}^{-1}$ on

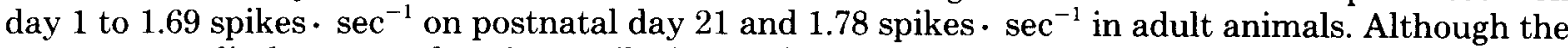
spontaneous discharge was low, interspike interval histograms were constructed for a sample of cells. Their modal value varied from a mean value of $660 \mathrm{msec}$ on day 1 to $250 \mathrm{msec}$ in the adult with, however, marked variations at each age in the young animals.

Intracellular recordings from PCs were performed in rats ranging in age from 5 to 15 postnatal days. The spontaneous (i.e., asynchronous) discharge of excitatory postsynaptic potentials mediated through climbing fibers (CF-EPSPs) was measured and compared to the discharge of inferior olivary neurons at the same age. The main results are the following: (1) In PCs innervated by one CF, the mean frequency of CF-EPSPs was similar to the discharge of inferior olivary neurons; (2) in PCs innervated by several CFs, the mean discharge of CF-EPSPs was much higher than the discharge of inferior olivary neurons; (3) as a whole, the CF-mediated activity of PCs decreased from day 5 to day 11, while the multiple innervation disappeared; from then on, the activity increased with the maturation of inferior olivary neurons until adult values. The ratio of the frequencies of CF-EPSPs and olivary neuron discharges gives an approximate mean number of CF collaterals per PC at each age; it varied from 3.6 on day 5 to values close to 1 on day 11 and the following days.
\end{abstract}

The climbing fibers (CFs) which originate mainly, if not exclusively, from the contralateral inferior olivary (IO) nucleus, at least in rodents (Desclin, 1974), represent one of the two main afferent systems of the cerebellar cortex (Ramon y Cajal, 1911) and exert a powerful excit-

${ }^{1}$ We wish to thank Drs. P. Benuit, J. L. Popot, and C. E. Henderson for helpful discussions, Simone Mougeon for expert technical assistance, Tania Sciuto for typing the manuscript, and P. Lemoine for photographic assistance. This work was supported by grants from the College de France, the Délégation Générale à la Recherche Scientifique et Technique, the Centre National de la Recherche Scientifique (ATP "Petits Mammifères"), the Institut National de la Santé et de la Recherche Médicale, and the Commissariat à l'Energie Atomique.

${ }^{2}$ Chargé de Recherche, Institut National de la Santé et de la Recherche Médicale. To whom correspondence should be addressed at Institut Pasteur, Département de Biologic Moléculaire, 25, rue du Dr. Roux, 75724 Paris Cedex 15, France. atory action on cerebellar Purkinje cells (PCs) (Eccles et al., 1966).

Since each PC receives only one CF in the adult mammal (Ramon y Cajal, 1911; Eccles et al., 1966), the classical climbing fiber response (CFR) of PC discharge reflects the discharge of one olivary cell at the adult stage. Some reports of the spontaneous discharge of IO cells in adult cats (Armstrong, 1974), rats (Headley et al., 1976), and mice (Mariani, 1980) exist, although the spontaneous activity of PCs has been studied more extensively (review in Armstrong, 1974; see also Belcari et al., 1977; Mariani and Delhaye-Bouchaud, 1978; Armstrong and Rawson, 1979).

During the development of olivocerebellar relationships, a transient multiple innervation of each PC by several CFs has been described in rats (Crépel et al., 1976; Mariani and Changeux, 1980). Thus, the CF-me- 
diated activity of these multiply innervated PCs is not identical to the spontaneous discharge of $\mathrm{IO}$ cells. Until now, data were available on neither the spontaneous activity of IO neurons during development nor the CFmediated activity of the PCs innervated by one or several CFs. The aim of the present work was to describe and to compare these two spontaneous patterns of activity in the developing rat.

\section{Materials and Methods}

Intracellular recordings of the spontaneous discharge of excitatory postsynaptic potentials mediated through climbing fibers (CF-EPSPs) from PCs in developing rats were obtained from cells used in the experiments presented in the accompanying paper (Mariani and Changeux, 1981).

Activity of IO neurons was recorded in Wistar rats from day 1 (day of birth = day 0 ) until adulthood at the ages indicated under "Results." Extracellular recordings from inferior olivary neurons were performed as described with staggerer mice (Mariani, 1980). The occipital bone was exposed, the atloido-occipital ligament was removed, and unitary extracellular recordings of IO neurons were performed through a dorsal approach near the midline. Glass micropipettes filled with 3 м potassium acetate and methyl blue were used and their DC resistance measured in situ was 15 to 30 megohms. The physiological state of the animals was controlled during all of the experiments as described in the companion paper (Mariani and Changeux, 1981). The data were photographed with a camera and stored on a magnetic tape for further statistical analysis.

Identification of 10 cells. During preliminary experiments, IO neurons were identified by their antidromic response after stimulation of the surface of the contralateral vermal surface as already described in mice (Mariani, 1980). However, since medial and dorsal accessory olives (MAO and DAO) constitute the main olivary projection to the cerebellar vermis (see, for example, Brodal, 1980), we decided to study only the neurons of these subnuclei for comparison with the activity of vermal PCs. Thus, it became necessary to identify the position of the cells recorded. In each experiment, one dye spot was made on each side by iontophoretic ejection of methyl blue and a maximum of 5 or 6 cells were recorded from a given animal; the unmarked cells were always located in the same sagittal plane as one of the spots, and their position was reconstructed from the depth indicated by the micromanipulator. Further identification of IO neurons was achieved from the shape of the responses (see "Results"). Moreover, in 1- and 3-day-old animals, the position of $80 \%$ of the cells recorded was marked by a dye spot.

Analysis of the data. Mean spontaneous discharge and interspike interval histograms of IO neurons were studied with a small computer (Intertechnique, Didac 800). Bin widths used were $10 \mathrm{sec}$ for mean discharge and 10 or 20 msec for interspike interval.

During the study of CF-EPSPs of PCs, a simple threshold system could not be used for counting, especially in the case of multiply innervated PCs where steps of different amplitude coexisted in the discharge, because of the multiwave shape of many of the spontaneous EPSPs.
A simple method was used: spontaneous EPSPs of a given $\mathrm{PC}$ were visualized on a memory scope and monitored through the audio system, with each sweep of the scope triggered by the rising edge of a given step. Each visualized and heard step was counted with a small manual counter. Whenever it was necessary (especially for multiply innervated PCs), the tape was used at a speed 2 or 4 times slower than the speed used for recordings; the appropriate correction of time scale was made later on.

\section{Results}

Ontogenesis of the spontaneous activity of inferior olivary neurons. Extracellular unitary recordings were obtained from a total of 249 neurons located in medial and dorsal accessory olives (MAO and DAO) of Wistar rats from 1 day old to adulthood. The shape of the unitary responses recorded extracellularly was nearly the same at all of the stages studied. As the microelectrode was advanced progressively toward the cell, the unitary action potential, initially negative, rapidly became positive-negative (Fig. $1 A_{1}$ ). The spontaneous activity of the cell was studied with this spike configuration. At the end of the recording, the microelectrode was advanced further and the response became purely positive with a sharp rising spike followed by a plateau on which wavelets sometimes appeared (Fig. $1, A_{2}, A_{3}, C$, and $D_{2}$ ). After this plateau, a negative wave appeared whose duration was about 80 to $150 \mathrm{msec}$ (Fig. $1, A_{3}$ and $C$ ). This positive configuration was observed, in our sample of cells, as early as postnatal day 1; its amplitude was usually 5 to $10 \mathrm{mV}$, even in young animals, but could reach 20 to 40 $\mathrm{mV}$, especially at older stages (after 11 to 13 days). As already discussed (Mariani, 1980), this configuration resembles the intracellular responses obtained in the cat (Crill, 1970; Llinas et al., 1974) and probably corresponds to an electrode tip closely apposed to the cell membrane. This was confirmed in some cells from which DC poten-
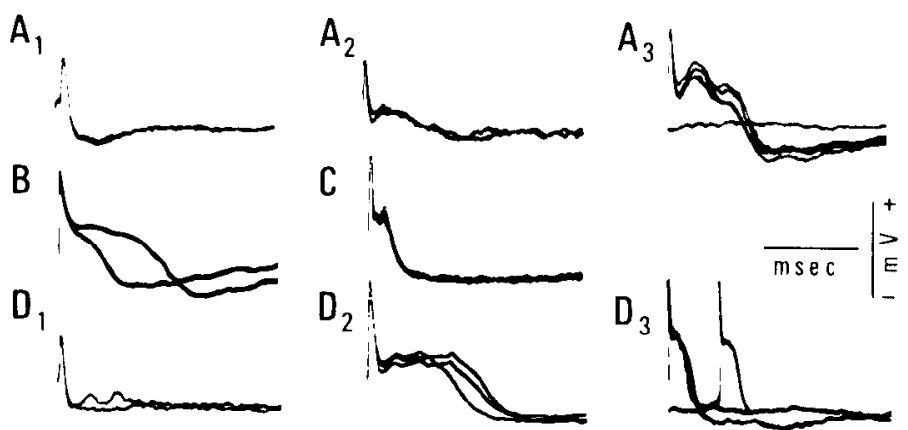

Figure 1. Unitary recordings of spontaneous discharge of inferior olivary neurons in developing rats. Several sweeps are superimposed in all traces and each sweep is triggered by the rising edge of the response. $A_{1}$ to $A_{3}$, IO neuron recorded extracellularly in a 1-day-old rat. The morphology of the response changed from $A_{\mathrm{I}}$ to $A_{3}$ while the microelectrode was advanced toward the cell (see text). $B$ and $C$, IO neurons recorded with the electrode presumably very close to the cell in 5 - $(B)$ and 10- $(C)$ day-old rats. $D_{1}$ to $D_{33}$, Olivary discharges obtained from an IO neuron in a 15-day-old rat. $D_{1}$ and $D_{2}$ were extracellular recordings. $D_{3}$ was obtained after penetration of the same cell. Calibration: horizontal bar, $20 \mathrm{msec}$ in $A_{1}$ to $A_{3}$, $B, D_{1}$, and $D_{2} ; 40 \mathrm{msec}$ in $C$; and $80 \mathrm{msec}$ in $D_{33}$.Vertical bar, 8 $\mathrm{mV}$ in $A_{1}$ to $A_{3}, B, C$, and $D_{1} ; 20 \mathrm{mV}$ in $D_{2} ; 40 \mathrm{mV}$ in $D_{3}$. 
tial shift and full spike intracellular response were obtained with a further small advance of the microelectrode (Fig. $1 D_{3}$ ).

The spontaneous discharge of the units was studied during intervals as long as $40 \mathrm{~min}$ but never shorter than $10 \mathrm{~min}$. Examples of the discharge of IO neurons at four different ages are illustrated in Figure $2 A(P N 1,5,11$, and 17 ). The evolution with age of the mean discharge rate is illustrated in Figure $3 A$. The mean discharge was very low in newborn animals and increased more or less regularly from 0.19 spike/sec on day $1(n=16, \mathrm{SD}=$ $0.168)$ to 1.67 spikes/sec on day $21(n=18, \mathrm{SD}=0.28)$. This last value did not differ significantly from the value found in adult rats (i.e., 1.78 spikes/sec, $n=22, \mathrm{SD}=$ $0.36)$.

Interspike interval histograms were constructed from only some of the cells recorded, since a minimal number of events was necessary to obtain clear-cut peaks on the histograms and since the activity of the cells was low, especially until days 9 and 10 . On postnatal days 1 and 3 , most of the histograms were obtained from particularly
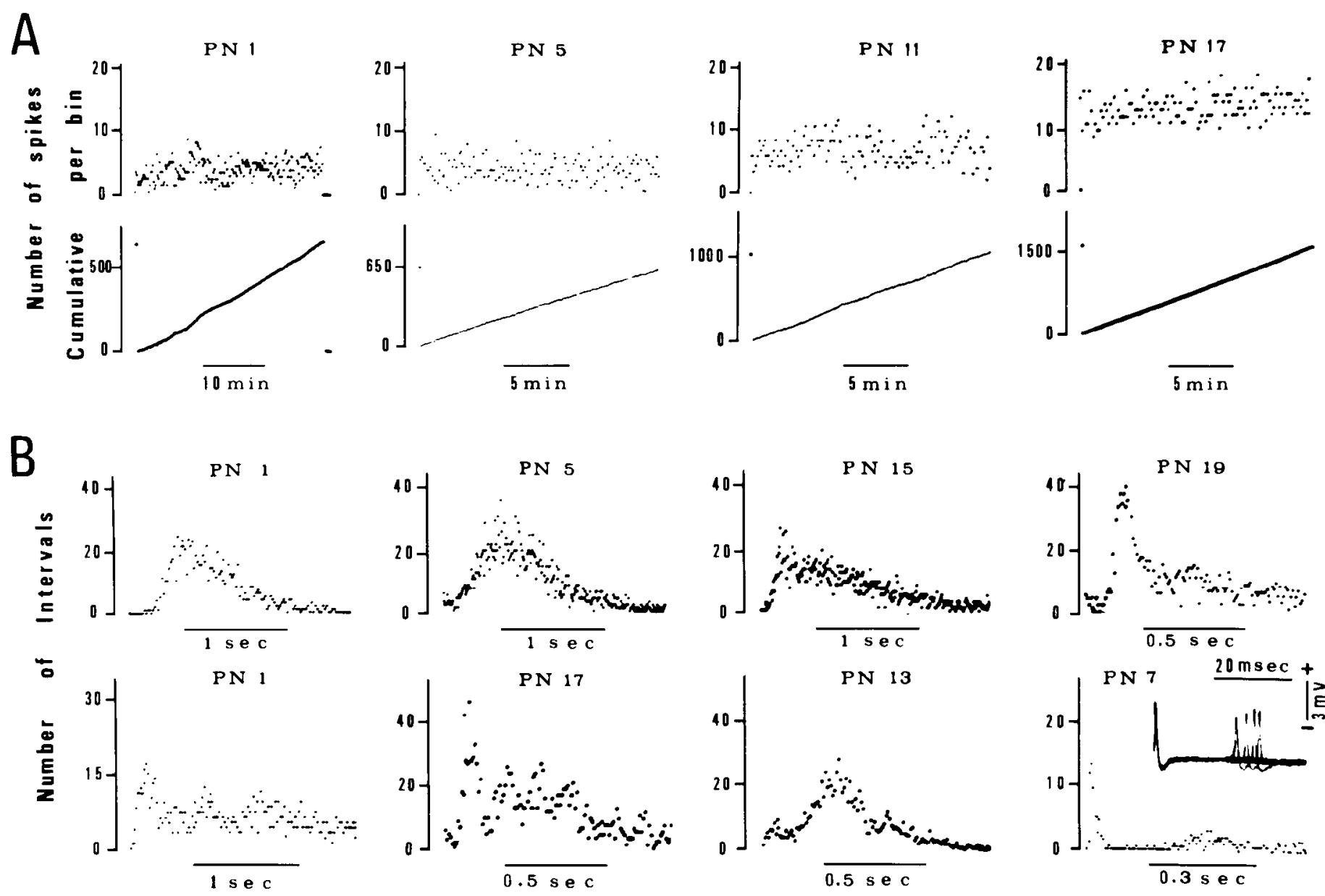

long recordings ( 30 to $40 \mathrm{~min}$ ) of the most active $I O$ cells;
thus, the sample could be somewhat biased. A total of 137 histograms was studied through development; they were always skewed with a more or less pronounced tail to the right. Most of these histograms were unimodal as illustrated in Figure 2B, upper row. The remaining histograms exhibited two or sometimes three peaks, the highest one being most often the first or sometimes the second depending on the cells (Fig. $2 B$, lower row). The evolution with age of the mean values of the mode is illustrated in Figure $3 B$.

Large variability appeared especially from day 1 to day 8 , around 600 to $700 \mathrm{msec}$, and an apparently abrupt decrease of the mean peak value occurred around postnatal days 9 and 10 when values similar to the adult ones were reached (around $300 \mathrm{msec}$ ). Furthermore, for a few cells recorded on postnatal day 7 and the following days, an early sharp peak appeared in the histograms (Fig. $2 B$, $P N 7$ ) and it corresponded to a repetitive activity of IO neurons at short intervals of about 20 to $40 \mathrm{msec}$ as already described in adult mice (Mariani, 1980).
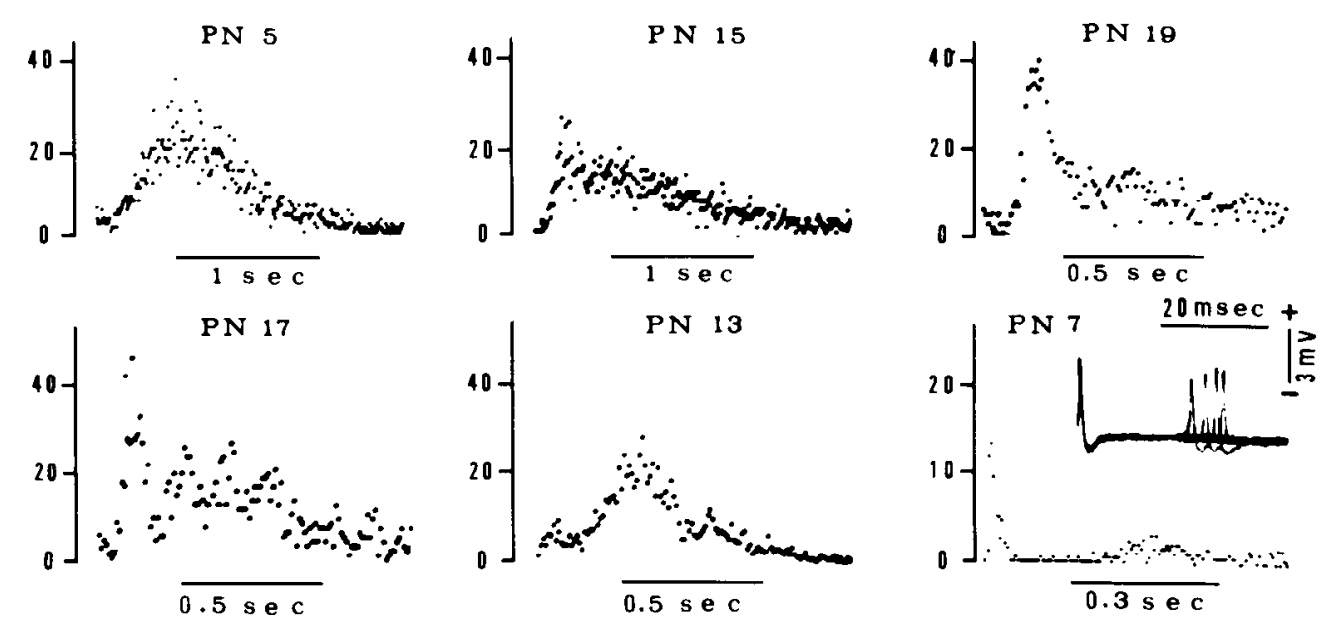

Figure 2. Spontaneous activity of IO neurons in developing rats. A, Frequency histograms of discharges recorded from IO cells at the indicated postnatal days $(P N 1,5,11$, and 17) (bin width $=10 \mathrm{sec})$. Note the progressive increase in the level of activity throughout development. Under each histogram, the cumulative frequency distributions of the corresponding cells illustrate the regularity of the spontaneous discharge throughout development. $B$, Interspike interval histograms of IO neurons recorded at the indicated postnatal days $(P N)$. The bin widths used were $10 \mathrm{msec}$ in all histograms except those for $P N 1$ and $P N 7$ where they were 20 and $6 \mathrm{msec}$, respectively. The upper row corresponds to the unimodal type of histograms; the lower row relates to the multimodal one. In the first two examples ( $P N 1$ and $P N 17)$ of multimodal histograms, the highest peak is the first one, while in the third example ( $P N$ 13), it is the second one. $P N 7$ disclosed an early peak in the histogram at 24 msec, corresponding to the repetitive discharge illustrated in the inset. Sampling times for interval histograms were between 20 and 33 min except for $P N 13$ (14 min). 

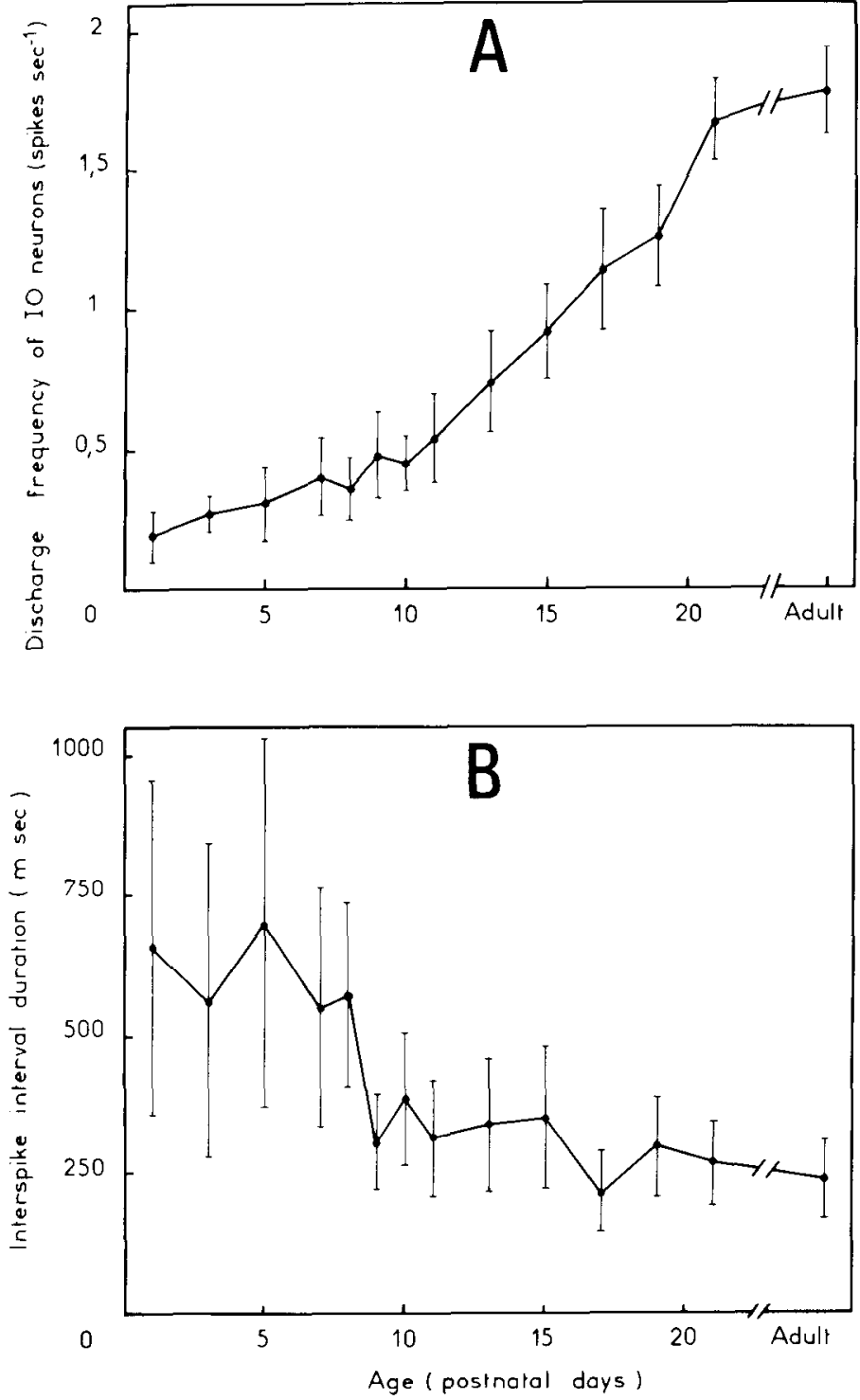

Figure 3. Evolution with age of the spontaneous discharge of IO neurons in developing rats. $A$ represents the evolution of the mean discharge frequency; each value is the mean of 14 to 25 cells. $B$ represents the evolution of the mode of interspike interval histograms; each value is the mean of 9 to 17 cells. Vertical bars represent the confidence limit interval of the mean at each age (at $95 \%$ ).

Ontogenesis of climbing fiber-mediated activity of Purkinje cells. The expression "spontaneous EPSPs" refers to EPSPs recorded from the background discharge of PCs while no electrical stimulation was applied to the CF pathway.

As already described in the companion paper (Mariani and Changeux, 1981), two populations of PCs were recorded, those in which spontaneous (and evoked) EPSPs had an all-or-none behavior (Fig. $4 A$ ) and the PCs whose EPSPs exhibited a stepwise variation in amplitude (Fig. $4, B, C$, and $D$ ).

Interstep interval histograms were not constructed in developing rats, but it was clear from a qualitative point of view that the different CF-EPSPs tended to occur in a burst-like fashion in many cells (Fig. $4, B_{2}, D_{1}$, and $D_{2}$ ). It should be noticed that every effort was made to observe the small steps preceding higher ones (Fig. $4 B_{1}$ ) since, even in singly innervated PCs, when two EPSPs occurred with a short separation, the size of the second one often was reduced slightly (not illustrated). Although evoked inhibitory postsynaptic potentials (IPSPs) were observed first on day 7 and more commonly on day 9 and the following days (Mariani and Changeux, 1981), spontaneous CF-EPSPs were followed by slight hyperpolarization as early as day 5 (Fig. $4, C_{1}$ and $C_{3}$ ).

The spontaneous discharge of CF-EPSPs was studied from $130 \mathrm{PCs}, 12$ recorded in 21-day-old rats and 118 of the 310 cells used in the related research. The reduced
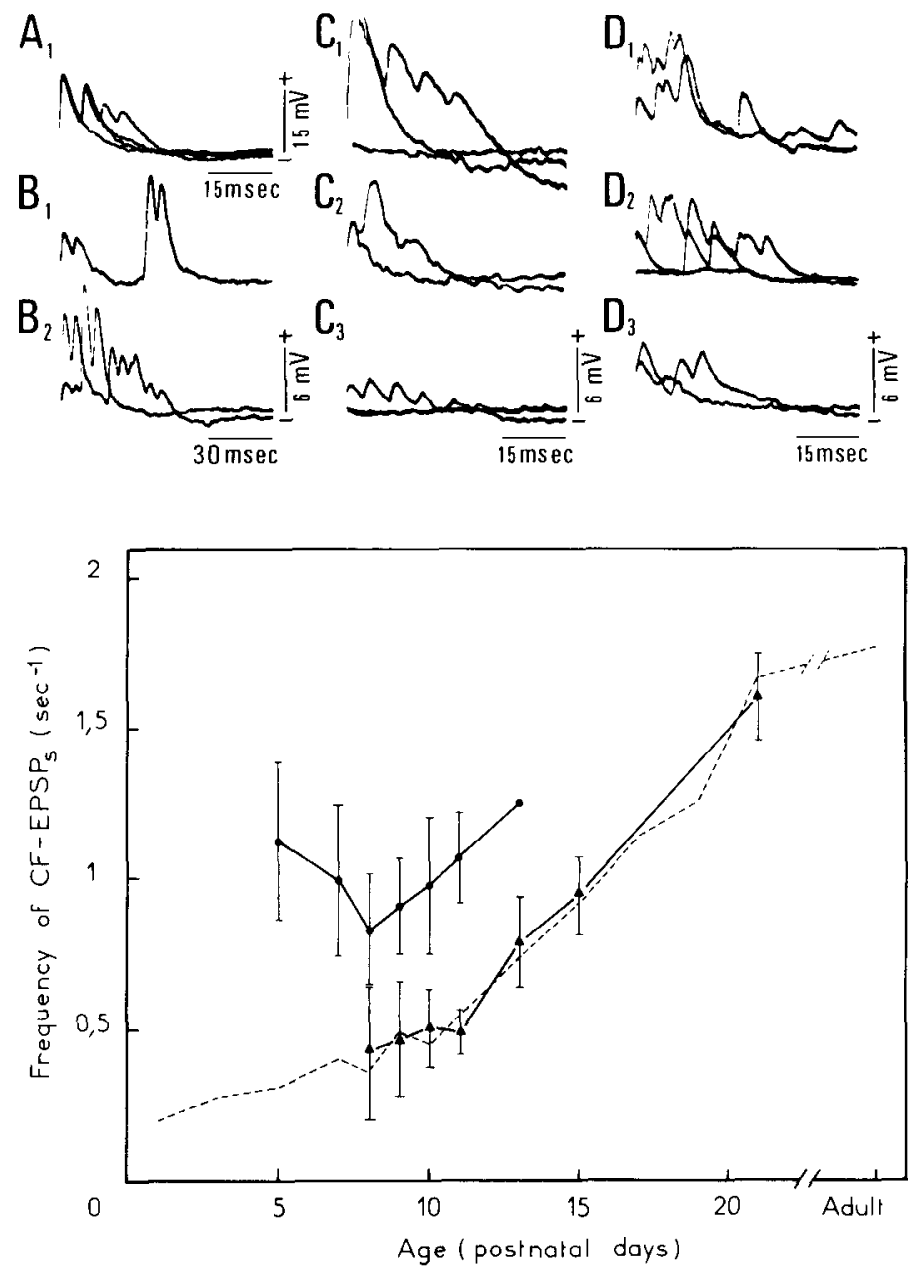

Figure 4. Intracellular recording of spontaneously occurring CF-EPSPs in developing rats. Several sweeps are superimposed in all traces and each sweep is triggered by the rising edge of the response. $A_{1}$, All-or-none typical CF-EPSP recorded from an 11-day-old rat. $B_{1}$ and $B_{2}$, CF-EPSPs recorded in a 9-dayold rat. Their sizes fluctuated in a stepwise manner. Note that, in $B_{1}$, the small step precedes the high one. $C_{1}$ to $C_{3}$, Different steps of CF-EPSPs recorded in a 5-day-old rat. Note that even the small step exhibits a multiwave shape. $D_{1}$ to $D_{3}$, Spontaneous EPSPs in a 7-day-old animal. The superimposition of different steps $\left(D_{1}\right.$ and $\left.D_{2}\right)$ gives more complex shapes. The graph illustrates the evolution with age of the mean discharge of spontaneous CF-EPSPs in Purkinje cells. - Multiply innervated PCs; each value is the mean of 9 to 12 cells except for days 11 ( 4 cells) and 13 ( 2 cells). $\boldsymbol{\Delta} \longrightarrow \boldsymbol{\Delta}$, Singly innervated PCs; each value is the mean of 10 to 18 cells except for day 8 (5 cells). The dashed line reproduces the evolution of the IO neuron discharge of Figure $3 A$. Vertical bars are as in Figure 3. No bar was indicated on day 13 for multiply innervated PCs because of the small number of these cells. 
number of cells conserved for the measurement of the spontaneous activity is explained by the following: (1) We retained only cells in which at least 2 min of stable intracellular recording of spontaneous CF-EPSPs could be obtained; too few cells were counted on days 3 and 4 and these stages were discarded. (2) On the other hand, on postnatal days 13 to 15 , we found that counting only 35 of the 100 cells recorded was sufficient for the purpose of the present study. (3) The PCs in which "dual" CFEPSPs were recorded were not used for counting since, as already discussed by Puro and Woodward (1977a), dual responses might correspond either to one CF-EPSP or to several CF-EPSPs originating from different fibers.

The evolution of CF-evoked activity of PCs during development is summarized in Figure 4. The mean discharge rate in PCs that exhibited all-or-none CF-EPSP was studied from days 8 to 21 and fitted well with the spontaneous discharge of IO neurons at the same age. On the contrary, the activity presumably evoked through CFs in PCs whose EPSPs were graded stepwise was strikingly higher than the activity of IO neurons at the same age. The mean CF-EPSP discharge decreased slightly from days 5 to 8 and then increased regularly until postnatal day 13 , the age at which the last multiply innervated $\mathrm{PCs}$ were recorded.

When the mean CF activities of singly and multiply innervated PCs of a given age were pooled, taking into account the respective percentage of multiple innervation at this age (see Mariani and Changeux, 1981), the result (Fig. $5 A$ ) gave a rough estimate of the CF-evoked activity of the whole population of PCs during development. This activity was clearly higher than the activity of the IO neurons until day 11; on day 11 and thereafter, the two activities became nearly identical, since very few cells exhibited CF-EPSPs with several steps. At each age, the ratio between IO and PC activities can be taken as an estimate of the mean number of functional CFs impinging on the whole population of PCs. The mean number of CF collaterals decreased from 3.57 on day 5 to 1.46 on day 9 and finally reached 1 on day 15 . This evolution fitted closely with the evolution of the mean number of steps in the EPSPs elicited by electrical stimulation of the $C F$ pathway (Fig. 5B; Mariani and Changeux, 1981).

\section{Discussion}

The spontaneous discharge of IO neurons and the spontaneous climbing fiber response (CFR) of PCs have been described already in adult animals from several species (Armstrong, 1974; Headley et al., 1976; Belcari et al., 1977; Mariani and Delhaye-Bouchaud, 1978; Armstrong and Rawson, 1979; Mariani, 1980). This paper deals with the spontaneous discharge of inferior olivary neurons and with the spontaneous synaptic activities recorded from $\mathrm{PCs}$ during postnatal development in rat.

The evidence indicating that the synaptic activities recorded from PCs throughout development were mediated through CFs has been presented in the companion paper (Mariani and Changeux, 1981) in which other modes of synaptic organization that might account for stepwise graded EPSPs have been discussed. It should be added that the excellent agreement between the mean discharge of EPSPs recorded in PCs innervated by one $\mathrm{CF}$ and the mean olivary discharge at the same age, even in the adult, strengthens the hypothesis that the synaptic activities recorded, indeed, were mediated through CFs.

Spontaneous activity of olivary neurons in developing rats. The cytological organization of the IO nucleus is already well established at birth (Altman and Bayer, 1978); nevertheless, the level of spontaneous activity in the accessory olives is very low at this age. The almost 10 -fold increase of activity that leads to the adult value on postnatal day 21 might reflect both the development of the autorhythmic properties of olivary neurons (Llinas and Yarom, 1980) basically of dendritic origin (Llinas
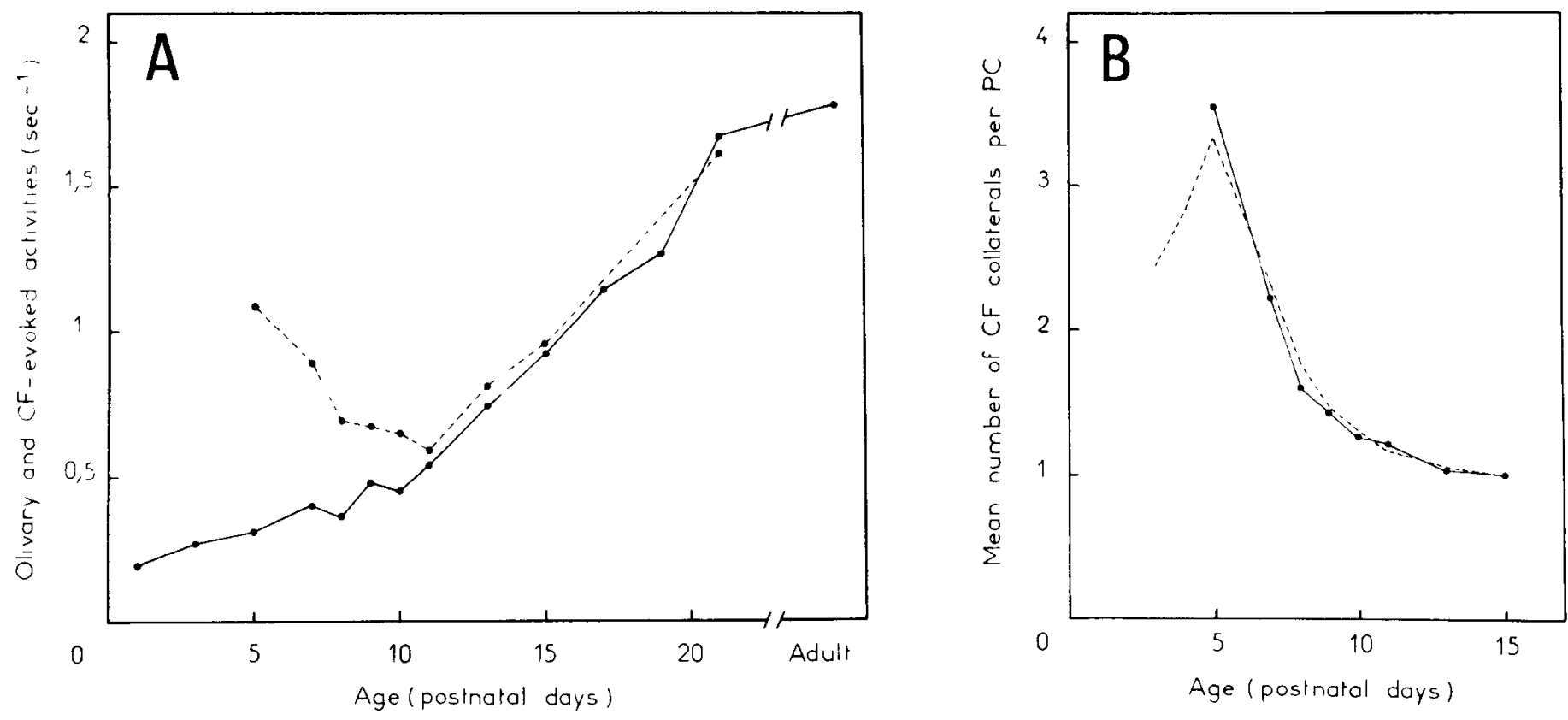

Figure 5. Comparative study of olivary and Purkinje cell spontaneous discharges. $A$, Evolution with age of spontaneous discharge of IO neurons (-) versus CF-mediated discharge ( - - $)$ ) of the global population of PCs (see text for details). $B$, Mean number of $\mathrm{CF}$ collaterals per PC estimated by the ratio between IO and PC discharges (O- Note the good agreement with the value determined using the mean number of steps in the evoked response (dashed line). 
and Sugimori, 1980b) and the maturation of the activity of afferent pathways to the IO nucleus. Morphological data on the maturation of such olivary afferences are scarce and concern only monkey (Robertson and Stotler, 1974) or opossum (Martin et al., 1980). However, Puro and Woodward (1977a) have demonstrated that, in the rat, transmission from both the periphery and sensorimotor cortex through the climbing fiber system to the Purkinje cells is found as early as postnatal day 3 but with immature features that change progressively during the first 2 postnatal weeks.

The organization of the spontaneous discharge of olivary neurons was investigated through the study of interspike interval histograms in adult and developing rats. In adult animals, the IO neurons tend to fire phasically, and one or sometimes more peaks of increased discharge probability appear at intervals that are multiples of a basic one, as already described in several other species (Armstrong, 1974; Belcari et al., 1977; Bell and Kawasaki, 1972; Mariani, 1980). Throughout development, the pattern of activity of IO neurons appears qualitatively similar to the adult one; the histograms were skewed toward longer intervals and showed one or more peaks of increased discharge probability. Although large variations existed in very young animals, the modal value of the interval histograms decreased rather abruptly on postnatal days 9 and 10 and reached values similar to the adult ones. At the same age, evoked repetitive climbing fiber inputs were recorded at intervals of 200 to $300 \mathrm{msec}$ (Puro and Woodward, 1977a); these values were similar to the ones found for interspike interval peaks at the same stage. On day 7 , repetitive discharges of IO cells at short intervals were first observed (Fig. $2 B, P N 7$ ) which might cause the "dual" EPSPs recorded from PCs from the same postnatal days (see Mariani and Changeux, 1981). It is also after the end of the 1st postnatal week that synchronization was noticed between high frequency bursts recorded from neighboring PCs (Dupont and Crépel, 1979) and that harmaline becomes able to elicit tremor and rhythmical olivocerebellar discharges in rats (Henderson and Wooley, 1970; Knowles and Phillips, 1980; J. Mariani, unpublished data) and rabbits (Barragan and Delhaye-Bouchaud, 1980).

As a whole, these data suggest that the cellular mechanisms or the neural organization necessary for the rhythmical and synchronized discharges of inferior olivary neurons were established mainly at 7 to 10 days, although they could already be effective at carlier stages for some cells (see Fig. $2 B, P N 1$ ).

Spontaneous CF-EPSPs in PCs of developing rats. A salient feature of $\mathrm{PCs}$ which exhibited stepwise graded CF-EPSPs is a clear-cut increase in the discharge of spontaneously occurring synaptic potentials in comparison with the discharge of IO neurons or PCs with a onestep CF-EPSP at the same age. This increased activity was observed transiently during normal development from the earliest stages tested (5 days) until 11 to 13 days. The stepwise variation of spontaneously occurring CF-EPSPs provides additional evidence for a transient multiple innervation of PCs by CFs (Crépel et al., 1976; Mariani and Changeux, 1981). Stepwise variation of CFEPSPs could result also from the innervation of a $\mathrm{PC}$ by several collaterals of the same climbing fiber with a conduction failure occurring intermittently at the level of the branching, as already demonstrated for other axons (Parnas et al., 1969; Van Essen, 1973; Westerfield et al., 1978). In this situation, the mean discharge rate of the steps would not be higher than the discharge of IO neurons at the same age. The increased discharge of CFEPSPs disclosed in this work supports the idea also suggested by former collision experiments that most of the CF collaterals converging on a PC belong to different IO neurons (Crépel et al., 1976).

The development of the overall spontaneous activity of PCs (Crépel, 1972) results from both possible endogenous properties of autorhythmicity (Llinas and Sugimori, $1980 \mathrm{a}, \mathrm{b})$ and synaptic activation of the PCs through their main afferences, first the CFs and then, after day 7 , the mossy fiber-parallel fiber system (Puro and Woodward, 1977b). Our results indicate that, although the overall spontancous activity of PCs augments during development (Crépel, 1972), the evolution of the activity through a given synaptic system might be more subtle. The evolution of CF-mediated synaptic activities in PCs during development results from two phenomena acting in opposite directions, the maturation of 10 cells that acquire the properties of an oscillator (Llinas and Yarom, 1980) and the regression of supernumerary collaterals of CFs. It should be noticed that most of the regression occurs around days 7 to 10 during the appearance of the rhythmical features of the olivary discharge.

Throughout this regression, the comparison of $\mathrm{CF}$ mediated spontaneous activity of $\mathrm{PCs}$ and $\mathrm{IO}$ neurons shows an excellent agreement with the data obtained frum the study of the evoked CF-EPSPs (Mariani and Changeux, 1981). The mean number of PCs innervated by one IO neuron (the "olivary unit") decreases by a factor of about 4 during development. Since, in adult rat (Schild, 1970), the mean size of olivary unit is about 6 PCs and since no death of PCs has been described at the same period, our data suggest that the mean olivary unit is about $24 \mathrm{PCs}$ when the multiple innervation is maximal.

In peripheral systems, recent experiments have shown that neural spontaneous activity might regulate several steps of synapse formation (see review in Changeux, 1979), including synapse elimination (Benoit and Changeux, 1975, 1978; O'Brien et al., 1978; Thompson et al., 1979). In the central nervous system, it has been well established that "peripherally evoked" activity plays a role during critical periods for the maintenance of functional characteristics of cortical visual cells (Wiesel and Hubel, 1965), although the underlying synaptic events have not been elucidated yet. It is tempting, although still speculative, to consider that the functional activity of the developing olivocerebellar network might regulate, directly or indirectly, the specification of the adult connectivity (Changeux and Danchin, 1976).

\section{References}

Altman, J., and S. A. Bayer (1978) Prenatal development of the cerehellar system in the rat. II. Cytogenesis and histogenesis of the inferior olive, pontine gray and the precerebellar reticular nuclei. J. Comp. Neurol. 179: 49-76.

Armstrong, D. M. (1974) Functional significance of connections of the inferior olive. Physiol. Rev. 54: 358-417. 
Armstrong, D. M., and J. A. Rawson (1979) Activity patterns of cerebellar cortical neurones and climbing fibre afferents in the awake cat. J. Physiol. (Lond.) 289: 425-448.

Barragan, L. A., and N. Delhaye-Bouchaud (1980) Harmaline induced activation of the olivo-cerebellar system in young rabbits: Further evidence for a transient multi-innervation of Purkinje cells by climbing fibres. Neuropharmacology 19: 305-310.

Belcari, P., A. Francesconi, C. Maioli, and P. Strata (1977) Spontaneous activity of the Purkinje cells in the pigeon cerebellum. Pfluegers Arch. 371: 147-154.

Bell, C. C., and T. Kawasaki (1972) Relations among climbing fiber responses of nearby Purkinje cells. J. Neurophysiol. 35: 155-169.

Benoit, P., and J. -P. Changeux (1975) Consequences of tenotomy on the evolution of multiinnervation in developing rat soleus muscle. Brain Res. 99: 354-358.

Benoit, P., and J. -P. Changeux (1978) Consequences of blocking the nerve with a local anesthetic on the evolution of multiinnervation at the regenerating neuromuscular junction of the rat. Brain Res. 149: 89-96.

Brodal, A. (1980) Olivocerebello-cortical projection in the cat as determined with the method of retrograde axonal transport of horseradish peroxidase. 2. Topographical pattern in relation to the longitudinal subdivision of the cerebellum. In The Inferior Olivary Nucleus: Anatomy and Physiology, J. Courville, C. de Montigny, and Y. Lamarre, eds., pp. 187-205, Raven Press, New York.

Changeux, J. -P. (1979) Molecular interactions in adult and developing neuromuscular junction. In The Neurosciences, Fourth Study Program, pp. 749-778, MIT Press, Cambridge, MA.

Changeux, J. -P., and A. Danchin (1976) Selective stabilization of developing synapses, a mechanism for the specification of neuronal networks. Nature 264: 705-712.

Crépel, F. (1972) Maturation of the cerebellar Purkinje cells. I. Postnatal evolution of the Purkinje cell spontaneous firing in the rat. Exp. Brain Res. 14: 463-471.

Crépel, F., J. Mariani, and N. Delhaye-Bouchaud (1976) Evidence for a multiple innervation of Purkinje cells by climbing fibres in the immature rat cerebellum. J. Neurobiol. 7: 567578.

Crill, W. E. (1970) Unitary multiple-spiked responses in cat inferior olive nucleus. J. Neurophysiol. 33: 199-209.

Desclin, J. (1974) Histological evidence supporting the inferior olive as the major source of cerebellar climbing fibers in the rat. Brain Res. 77: 365-384.

Dupont, J. L., and F. Crépel (1979) Correlations among climbing fiber responses of nearby cerebellar Purkinje cells in the immature rat. Exp. Brain Res. 37: 525-535.

Eccles, J. C., R. Llinas, and K. Sasaki (1966) The excitatory synaptic action of climbing fibers on the Purkinje cells of the cerebellum. J. Physiol. (Lond.) 182: 268-296.

Headley, P. M., D. Lodge, and A. W. Duggan (1976) Druginduced rhythmical activity in the inferior olivary complex of the rat. Brain Res. 101: 461-478.

Henderson, G. L., and D. W. Wooley (1970) Ontogenesis of drug-induced tremor in the rat. J. Pharmacol. Exp. Ther. 175: 113-120.

Knowles, W. D., and M. I. Phillips (1980) Neurophysiological and behavioral maturation of cerebellar function studied with tremorogenic drugs. Neuropharmacology 19: 745-756.

Llinas, R., and M. Sugimori (1980a) Electrophysiological properties of in vitro Purkinje cell somata in mammalian cerebellar slices. .J. Physiol. (Tond.) 305: 171-195.

Llinas, R., and M. Sugimori (1980b) Electrophysiological prop- erties of in vitro cell dendrites in mammalian cerebellar slices. J. Physiol. (Lond.) 305: 197-213.

Llinas, R., and Y. Yarom (1980) Electrophysiological properties of mammalian inferior olivary cells in vitro. In The Inferior Olivary Nucleus: Anatomy and Physiology, J. Courville, C. de Montigny, and Y. Lamarre, eds., pp. 379-388, Raven Press, New York.

Llinas, R., R. Baker, and C. Sotelo (1974) Electrotonic coupling between neurons in cat inferior olive. J. Neurophysiol. 37: $560-571$.

Mariani, J. (1980) Electrophysiological study of inferior olivary neurons in slaggerer mulant mice. Exp. Brain Res. 38: 463468.

Mariani, J., and J. -P. Changeux (1980) Etude par enregistrements intracellulaires de l'innervation multiple des cellules de Purkinje par les fibres grimpantes dans le cervelet du rat en développement. C. R. Acad. Sci. (D) (Paris) 291: 97-100.

Mariani, J., and J. -P. Changeux (1981) Ontogenesis of olivocerebellar relationships: I. Studies by intracellular recordings of the multiple innervation of Purkinje cells by climbing fibers in the developing rat cerebellum. J. Neurosci. 1: 696702 .

Mariani, J., and N. Delhaye-Bouchaud (1978) Effect of diazepam on the spontaneous and harmaline-induced electrical activity of Purkinje cells in the cerebellum of the rat and rabbit. Neuropharmacology 17: 45-51.

Martin, G. F., J. Culberson, C. Laxon, M. Linauts, M. Panneton, and I. Tschismadia (1980) Afferent connections of the inferior olivary nucleus, with preliminary notes on their development. Studies using the North American oposum. In The Inferior Olivary Nucleus: Anatomy and Physiology, J. Courville, C. de Montigny, and Y. Lamarre, eds., pp. 35-72, Raven Press, New York.

O'Brien, R. A. D., A. J. C. Ostberg, and G. Vrbova (1978) Observations on the elimination of poly-neuronal innervation in developing mammalian skeletal muscle. J. Physiol. (Lond.) 282: 571-582.

Parnas, I., M. E. Spira, R. Werman, and F. Bergman (1969) Non-homogeneous conduction in giant axons of the nerve cord of Periplaneta americana. J. Exp. Biol. 50: 635-649.

Puro, D. G., and D. J. Woodward (1977a) Maturation of evoked climbing fiber input to rat cerebellar Purkinje cells. Exp. Brain Res. 28: 85-100.

Puro, D. G., and D. J. Woodward (1977b) Maturation of mossy fiber input to rat cerebellar Purkinje cells. Exp. Brain Res. 28: 427-441.

Ramon y Cajal, S. (1911) Histologie du système nerveux de l'homme et des vertébrés, Vols. I and II, Maloine, Paris.

Robertson, L. T., and W. A. Stotler (1974) The structure and connections of the developing inferior olivary nucleus of the rhesus monkey. J. Comp. Neurol. 158: 167-190.

Schild, R. F. (1970) On the inferior olive of the albino rat. J. Comp. Neurol. 140: 255-260.

Thompson, W., D. P. Kuffler, and J. K. S Jansen (1979) The effect of prolonged reversible block of nerve impulses on the elimination of polyneuronal innervation of new-born rat skeletal muscle fibers. Neuroscience 4: 271-281.

Van Essen, D. C. (1973) The contribution of membrane hyperpolarization to adaptation and conduction block in sensory neurones of the leech. J. Physiol. (Lond.) 230: 509-534.

Westerfield, M., R. W. Joyner, and J. W. Morre (1978) Temperature sensitive conduction failure at axon branch points. J. Neurophysiol. $41: 1-8$.

Wiesel, T. N., and D. H. Hubel (1965). Comparison of the effects of unilateral and bilateral eye closure on cortical unit responses in kittens. J. Neurophysiol. 28: 1029-1040. 